\title{
Mix-mode energy management strategy and battery sizing for economic operation of grid-tied microgrid
}

DOI:

10.1016/j.energy.2016.11.018

\section{Document Version}

Accepted author manuscript

Link to publication record in Manchester Research Explorer

\section{Citation for published version (APA):}

Sukumar, S., Mokhlis, H., Mekhilef, S., Naidu, K., \& Karimi, M. (2017). Mix-mode energy management strategy and battery sizing for economic operation of grid-tied microgrid. Energy, 118, 1322-1333.

https://doi.org/10.1016/j.energy.2016.11.018

\section{Published in:}

Energy

\section{Citing this paper}

Please note that where the full-text provided on Manchester Research Explorer is the Author Accepted Manuscript or Proof version this may differ from the final Published version. If citing, it is advised that you check and use the publisher's definitive version.

\section{General rights}

Copyright and moral rights for the publications made accessible in the Research Explorer are retained by the authors and/or other copyright owners and it is a condition of accessing publications that users recognise and abide by the legal requirements associated with these rights.

\section{Takedown policy}

If you believe that this document breaches copyright please refer to the University of Manchester's Takedown Procedures [http://man.ac.uk/04Y6Bo] or contact uml.scholarlycommunications@manchester.ac.uk providing relevant details, so we can investigate your claim.

\section{OPEN ACCESS}




\title{
Mix-Mode Energy Management Strategy and Battery Sizing for Economic
} Operation of Grid-Tied Microgrid

\author{
Shivashankar.S $^{\text {a }} \quad$ Hazlie Mokhlis ${ }^{a, *} \quad$ Saad Mekhilef $^{a} \quad$ K.Naidu $^{\text {a }} \quad$ M.Karimi ${ }^{\text {b }}$ \\ * Corresponding author at: Department of Electrical Engineering, Faculty of Engineering, \\ University of Malaya, 50603 Kuala Lumpur, Malaysia. Tel.: +60 3 79675238; fax: +60 3 \\ 79675316. E-mail Address: hazli@um.edu.my \\ ${ }^{a}$ Department of Electrical Engineering, University of Malaya, 50603 Kuala Lumpur, \\ Malaysia \\ ${ }^{\mathrm{b}}$ School of Electrical and Electronics Engineering, The University of Manchester, United \\ Kingdom
}

\begin{abstract}
This paper presents a novel 'mix-mode' energy management strategy (MM-EMS) and its appropriate battery sizing method for operating the microgrid at the lowest possible operating cost. The MM-EMS is developed by combining three proposed operating strategies, namely "continuous run mode", "power sharing mode" and "ON/OFF mode" for a $24 \mathrm{~h}$ time period. The objective functions for the proposed strategies are solved using linear programming (LP) and mixed integer linear programming (MILP) optimization methods. A sizing method using the particle swarm optimization (PSO) technique to determine the optimal energy capacity of battery energy storage (BES) in $\mathrm{kWh}$ is also presented. Since the size of the BES influences the microgrid's operating cost, the energy management strategy (EMS) and BES capacity are simultaneously optimized. The proposed MM-EMS and battery sizing method were first validated. Then, the variation of optimal battery capacity for different battery state of charge (SOC) levels is analyzed. The variation of microgrid's associated costs for different battery's
\end{abstract}


25 initial state of charge (SOC) levels is analyzed as well. Finally, a recommendation on the choice

26 of initial SOC level during the start of the day for the economic operation of microgrid is also

27 suggested.

28 Keywords

29 Energy management, battery storage, battery sizing, microgrids and particle swarm optimization 30 (PSO).

31 1. Introduction

32 The conventional power system distribution network is currently undergoing a major change due

33 to the addition of microgrids. The benefits of using microgrids include the fact that it is capable

34 of supplying loads with negligible losses, reduce fossil fuel consumption, and postpone

35 investment in a distribution system. Connecting intermittent sources such as solar photovoltaic

36 (PV) generators and wind turbines in the grid-connected microgrid introduces challenges in

37 various technical aspects, such as power quality, protection, generation dispatch control, and 38 reliability. Challenges caused by these intermittent sources render the battery energy storage 39 (BES) an indispensable source [1]. When a grid connected microgrid consists of two or more 40 dispatchable source, it is necessary for the grid operator to run it economically. If battery energy 41 storage (BES) is one of the dispatchable sources, it is essential that an appropriate size of BES is 42 installed for the optimal microgrid operation.

43 A power management and battery sizing algorithm is proposed for a grid connected microgrid, 44 consisting of PV, diesel generator, and BES in [2]. However, the battery size is not optimum, 45 because the algorithm does not consider economic operation of microgrid. A smart energy 46 management system based on matrix real-coded genetic algorithm is proposed in [3] for 47 economic operation of grid connected microgrid. The optimal operation of grid connected 
microgrid is presented in [4,5], where the microgrid's economic dispatch problem is solved by

49 minimizing the microgrid's operational cost using mesh adaptive direct search (MADS)

50 algorithm. Mixed integer linear programming (MILP) is used to solve the economic dispatch of

51 microgrid sources in [6]. An optimal energy management is presented in [7], where the objective

52 is to minimize the generation cost of the grid connected microgrid. The economic dispatch

53 problem is solved using mixed integer quadratic programming (MIQP). Similarly, the sizing of

54 battery energy storage is carried out in [8], where the economic dispatch problem is solved using

55 linear programming (LP). Apart from solving the energy management problem using numerical

56 methods, metaheuristic methods are used to solve energy management problem found in [9-12].

57 The energy management problem from the aforementioned references is based on one particular

58 strategy. Moreover, in few papers, the optimal sizing of battery storage is not taken into account.

59 Energy storage devices play a crucial role in the economic operation of microgrid. Battery

60 storage can take advantage of time of use tariffs, where it can be an effective option when the

61 power purchasing price from the utility grid is high. Therefore, the accurate sizing of battery

62 source is essential to ensure a microgrid's economic operation. The sizing of BES involves

63 determining the optimal energy capacity in $\mathrm{kWh}$ with the aim of reducing microgrid's daily

64 operating cost. An optimal sizing of battery storage for microgrid is presented in [13]. The

65 optimal sizing of battery energy storage using improved bat algorithm is presented in [14].

66 Genetic algorithm based method for sizing battery storage is proposed in [15]. The energy

67 management system in this paper is based on fuzzy expert system. In [16], matrix real-coded

68 genetic algorithm (MRCGA) is used to determine the optimal energy capacity of BES. In a

69 recently published article [17], the battery size is evaluated in order to minimize the microgrid's

70 operation cost. The sizing problem was solved using Grey Wolf Optimizer (GWO). The energy 
71 management problem solved in aforementioned references is based on a single operating

72 strategy. The battery sizing methods presented in these references is focused on one particular

73 energy management strategy, which may not incur the lowest operating cost.

74 The prominent focus of most work in literature pertaining to this subject was on solving 75 economic dispatch for microgrid sources using a single operating strategy. It is possible that the 76 microgrid might operate at lower operating cost in the case of a newly designed operating 77 strategy. There are only a few works in literature that accounted for the sizing of battery storage, 78 which is an important aspect of economic operation of a microgrid. In addition the papers in the 79 literature discuss battery sizing methods that considers the economic operation of microgrid for one particular strategy. Therefore, in this paper an energy management strategy to operate the 81 grid connected microgrid at the lowest possible operating cost is discussed. A method to estimate 82 optimal BES size in $\mathrm{kWh}$ will also be presented. This work involves the development of an 83 energy management using mix-mode operating strategy to operate the microgrid at the lowest 84 possible operating cost. The proposed mix-mode operating strategy is developed by combining 85 three proposed operating strategies, namely "continuous run mode", "power sharing mode" and 86 "ON/OFF mode" for a $24 \mathrm{~h}$ time period. The objective functions for these operating strategies 87 were minimized using linear programming (LP) and mixed integer linear programming (MILP) 88 methods. The mix-mode operating strategy is based on combining the aforementioned strategies 89 keeping the operating cost in mind. The non-linearity of the PV output power and load demand, 90 daily grid electricity price profile, the price of the natural gas, as well as battery state of charge 91 (SOC) limits were all taken into account in the development of this model. In this paper, the 92 BES's energy capacity for the microgrid under the proposed mix-mode operating strategy is 93 solved using the PSO optimization technique. Due to the fact that the operating cost produced 
94 using mix-mode strategy depends on the characteristics of battery storage, both the EMS and 95 BES capacity needs to be simultaneously optimized. The discussion section will detail the, validation of the proposed MM-EMS and battery sizing method. Then, the variation of the optimal battery capacity for different battery state of charge (SOC) level is analyzed. Also, an analysis on variation of microgrid's operating cost (OC), battery's total cost per day (TCPD), and the combined cost of OC and TCPD will be carried out for different values of initial SOC levels. Finally, a recommendation is also suggested on choice of battery's initial SOC level during start of the day.

\section{Proposed ‘Mix-Mode’ Energy Management Strategy (MM-EMS)}

Operating the microgrid in more than one operating strategy is referred to as the mix-mode operating strategy. Three operating strategies, namely the continuous run mode, power sharing mode, and ON/OFF mode are proposed and explained in the following subsections.

\subsection{Proposed operating strategies}

The optimal generation dispatch for energy sources is calculated on an hourly basis to satisfy the load requirements considering hybrid system limits and constraints. The proposed operating strategies are explained in the subsequent sections.

\subsubsection{Strategy 1: Continuous run mode}

In this operating mode, the power drawn from the utility grid is always zero. The fuel cell operates continuously during a $24 \mathrm{~h}$ time period. The output power from the fuel cell depends on the load demand and output powers from the PV and battery storage. During this strategy, initially the output power from PV and battery is used to supply the load demand. If demand is not met, the fuel cell is optimally dispatched to satisfy the load demand. There are chances where the output power from the PV exceeds the load demand, and in this case, the battery is charged, 
117 and the fuel cell is forcibly switched OFF. The objective function for this mode is to reduce the

118 daily operating cost, which can be expressed as:

$$
\operatorname{obj1}=\operatorname{Minimize}\left[C_{g i} \sum_{i=1}^{N} \frac{P_{F C i}}{\eta_{i}}+\beta\left(P_{B A T i}\right)\right]
$$

120 where,

$121 C_{g i}$ is natural gas price to supply the fuel cell in dollars per kilowatt-hour

$122 P_{F C i}$ is fuel cell power at time interval ' $i$ '

$123 \beta$ is taken as $1 \times 10^{-6}$ to obtain the dispatch solution of $P_{B A T i}$

$124 P_{B A T i}$ battery power at time interval ' $i$ ';

125 If $P_{B A T i}$ is positive battery discharges mode, if $P_{B A T i}$ is negative battery charging mode

$126 \eta_{i}$ is cell efficiency of SOFC at time interval ' $i$ ' which is given as,

$$
\eta_{i}=\frac{\left(\frac{V_{\text {stack }(i)}}{N}\right)}{E^{o}}
$$

$128 E^{o}$ is standard electrochemical potential which is $1.482 \mathrm{volt} / \mathrm{cell}$

$129 V_{\text {stack }}$ is fuel cell output stack voltage at instant ' $i$ '

$130 N$ is number of cell in fuel cell stack

131 At any given time instant ' $i$ ', the sum of the power generated from the distributed sources should

132 be equal to the load, which can be expressed as:

$$
P_{P V i}+P_{B A T i}+P_{F C i}=P_{L i} \quad i=1,2, \ldots 24
$$

134 The power produced from PV is uncontrollable. The fuel cell and battery is modeled as a 135 variable controllable source, which should be operated within the prescribed limits for a $24 \mathrm{~h}$ time 136 period. The constraints for the controllable source are given as: 


$$
P_{F C \min } \leq P_{F C i} \leq P_{F C \max } \quad i=1,2, \ldots 24
$$

138 The constraints related to battery energy level and allowable charge/discharge power considered 139 for this work will be explained in Section 3.

\subsubsection{Strategy 2: Power sharing mode}

141 In this power sharing mode, the utility grid, battery source, and fuel cell are all optimally 142 scheduled to supply power to the load demand. The battery source is charged when the output 143 power from the PV exceeds that of the load demand. The objective function for the power 144 sharing mode is to reduce the daily operating cost, which can be expressed as:

$$
\operatorname{obj} 2=\operatorname{Minimize}\left[C_{g i} \sum_{i=1}^{N} \frac{P_{F C i}}{\eta_{i}}+C_{e i}\left(P_{L i}-P_{n e t i}\right)+\beta\left(P_{B A T i}\right)\right]
$$

146 where,

$147 C_{e i}$ tariff of electricity purchased in dollar per kilowatt-hour

$148 P_{L i}$ is the load demand at interval ' $i$ '

$149 P_{\text {net } i}$ is the net power produced at interval ' $i$ '

150 At any instant of time ' $t$ ', the summation of total generated power from PV, fuel cell, battery 151 source and utility grid should be equal to the total load demand.

$$
P_{P V i}+P_{B A T i}+P_{F C i}+P_{G i}=P_{L i} \quad i=1,2, \ldots 24
$$

153 Since the microgrid operates at the distribution level, the excess power from the microgrid is 154 utilized to charge the battery. This is necessary to avoid the power from being injected to grid, 155 which will activate the reverse power flow relay installed at the point of common coupling 156 (PCC). The power imported from the grid at time instant ' $i$ ' can be used to charge the battery or 
157 supply the load. Therefore, considering the power drawn from the grid as a constraint which can 158 be expressed as,

$$
P_{G i} \geq 0 \quad i=1,2, \ldots .24
$$

160

161

162

163

164 165

166

167

168

169

170

171

172

Moreover, the boundary constraints for fuel cell given in eq.(4) are taken into account for this strategy. The limitations related to battery energy level and allowable charge/discharge power considered for this work will be explained in Section 3.

\subsubsection{Strategy 3: ON/OFF mode}

In this strategy, the objective is to obtain an optimal ON/OFF schedule for the fuel cell, utility grid, and battery source, thereby minimizing the microgrid's operating cost. Here, the output power from both the PV and battery source supplies the load demand. Any deficit in the power required by the load is delivered by optimally dispatching fuel cell and the utility grid. In this operating strategy, when the fuel cell is switched $\mathrm{ON}$, it is forced to run at its rated output power.

For the rest of the time, the fuel cell is switched OFF. Since the fuel cell is switched ON/OFF, a binary switching variable is introduced to enhance control over the fuel cell. The objective function for this ON/OFF mode is given as:

$$
\text { obj3 }=\text { Minimize }\left[S(i)\left(C_{g i} \sum_{i=1}^{N} \frac{P_{F C i}}{\eta_{i}}\right)+C_{e i}\left(P_{L i}-P_{n e t i}\right)+\beta\left(P_{B A T i}\right)\right]
$$

173 Where $S(i)$ is a switching function, which takes the value of 0 or 1 . When $S(i)$ is 1 , the fuel cell is 174 operated at its rated capacity. When $S(i)$ is 0 , the fuel cell is switched OFF. Therefore, during the 175 time of the fuel cell operation, its output is constant.

176 At any given time instant ' $i$ ', the sum of power generated from the distributed sources and utility 177 grid should be equal to the load, which can be expressed as: 


$$
P_{P V i}+P_{B A T i}+\left(P_{F C i}\right) S(i)+P_{G i}=P_{L i} \quad i=1,2, \ldots 24
$$

179 Since the fuel cell is forced to run at its rated capacity, the operating range of fuel cell is either 180 zero or at its rated capacity. The boundary constraint for utility grid power eq.(7) is also 181 considered. The limitations related to battery energy level and allowable charge/discharge power 182 considered for this work will be explained Section 3.

\subsection{Development of mix-mode operating strategy}

184 This section explains the development of "mix-mode" operating strategy. The primary objective 185 of mix-mode operating strategy is to dispatch power from the distributed sources to the varying 186 load with lower daily operating cost. The idea of mix-mode strategy is presented in Fig. 1. 187 Initially the forecasted PV output power and load demand for the time instant ' $i$ ' is considered. 188 For the given time instant with the PV power, load demand, prices of electricity and natural gas 189 as inputs, the economic dispatch problem is solved for the three proposed strategies. $O b j 1, O b j 2$, 190 and $O b j 3$ are the obtained objective functions for strategy 1, strategy 2 and strategy 3, 191 respectively, for the given time instant ' $i$ '. The lowest value of the three objective functions 192 should deliver the lowest operating cost. Therefore, the optimal dispatch values corresponding to 193 the lowest objective function is selected and provided as a reference to the distributed generators 194 present in the microgrid. The aforementioned steps are repeated for every time instant ' $i$ ' and this 195 microgrid is operated for $24 \mathrm{~h}$ time period. 


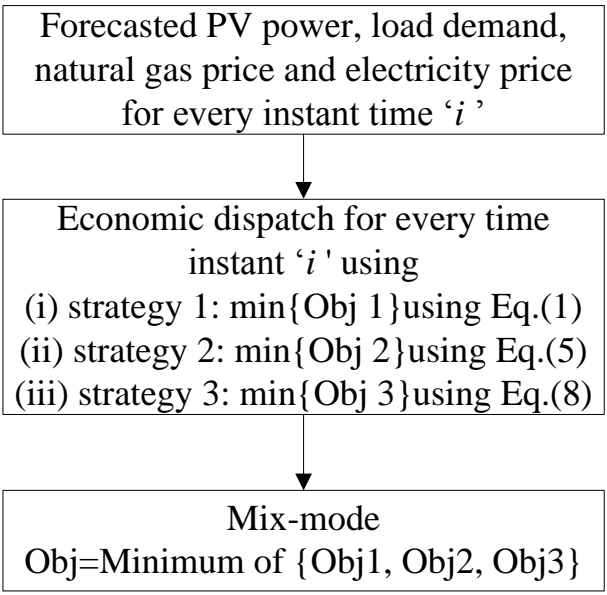

Fig.1. Mix-mode operating strategy

\section{Optimal sizing of battery source for MM-EMS: Problem formulation}

On top of the proposed energy management strategy, optimal sizing of BES for MM-EMS is also formulated. To obtain the optimal battery sizing, the initial capital cost (CC) of BES should be considered. Total cost per day for BES $\left(T C P D_{B A T}\right)$ is the function of initial capital cost of BES. The optimal BES sizing is obtained by minimizing the total cost function, which is a summation of the daily operating cost of microgrid and BES's $T C P D_{B A T}$. The daily operating cost of the microgrid $(O b j)$ is obtained from the previous section by operating the microgrid in the mixmode operating strategy. Therefore, the total cost function formulated for this problem can be

207 given as:

$$
\operatorname{Min} F(X)=\sum_{i=1}^{24} \operatorname{Obj}(i)+T C P D_{B A T}
$$

$$
\operatorname{TCPD}_{B A T}=\frac{1}{365}\left(\frac{r \cdot(1+r)^{L t}}{(1+r)^{L t}-1} \cdot C C\right)
$$

$$
C C=C_{P} \cdot \bar{P}+C_{E} \cdot \bar{E}
$$


213 where $C C$ is the capital cost of the battery source, and $C_{P}$ and $C_{E}$ are specific costs associated

214 with the battery source's power and energy capacities, respectively. $r$ is interest rate for financing

215 the battery source, $L t$ is the battery source's lifetime and $\bar{E}$ and $\bar{P}$ are rated energy and power

216 capacities of the BES.

217 The proposed sizing problem is solved subjected to constraint given below,

218 (a) Battery constraints:

219 The charge in the BES must be bounded between,

220

$$
E_{B A T}^{\min } \leq E_{B A T} \leq E_{B A T}^{\max }
$$

221 where $E_{B A T}$ is the energy stored in the battery at the end of instant ' $i$ ' in kWh.

$222 E_{B A T}^{\min }, E_{B A T}^{\max }$ are minimum and maximum charges to be maintained for battery storage

223 Discharging mode:

224 Constraint limited to release of energy from battery source is given as,

$$
E_{B A T, i}=\max \left\{\left(E_{B A T, i-1}-\Delta t . P_{B A T, i} / \eta_{\text {discharg } e}\right), E_{B A T}^{\min }\right\}
$$

\section{Charging mode:}

227 Constraint limited to energy stored in the battery source is given as,

$$
E_{B A T, i}=\min \left\{\left(E_{B A T, i-1}-\Delta t \cdot P_{B A T . i} \cdot \eta_{c h \text { arg } e}\right), E_{B A T}^{\max }\right\}
$$

229 In addition to the limitation in charging/discharging levels, the maximum and minimum discharging/charging power is also given as,

$$
P_{B A T, i}^{c} \leq P_{B A T, i} \leq P_{B A T, i}^{d} \quad i=1,2, \ldots N
$$

232 where,

$$
P_{B A T, i}^{c}=\max \left\{P_{B A T, \min },\left(E_{B A T, i-1}-E_{B A T}^{\max }\right) / \eta_{c h \text { arg } e} . \Delta i\right\} i=1,2, \ldots N
$$

$$
P_{B A T, i}^{d}=\min \left\{P_{B A T, \max },\left(E_{B A T, i-1}-E_{B A T}^{\min }\right) \eta_{\text {discharg } e} / \Delta i\right\} \quad i=1,2, \ldots . N
$$


$235 \Delta i$ is the commitment period which is $1 \mathrm{~h}$ in this paper

236 The proposed battery sizing problem should fulfill the aforementioned constraints in Eq.(13)-

237 (18) for solving the energy management strategy proposed in Section 2.

238 (b) Dispatchable distributed generator constraints

239 The PV source is uncontrollable, and its output depends on solar radiation. The operating output 240 of other dispatchable sources should be limited within the minimum and maximum limits. The 241 operating limits of the fuel cell and utility grid for the proposed strategies are provided in 242 corresponding Sections 2.1.1, 2.1.2, 2.1.3.

\section{4. Proposed sizing method}

244 In the ordinary form, solving the optimal BES sizing for the proposed mix-mode operating 245 strategy is a complex optimization problem. Therefore, the particle swarm optimization (PSO) 246 technique, which is a population based optimization technique, is used to solve the battery sizing 247 problem. The economic dispatch problems proposed in the three strategies are solved using 248 linear programming (LP) and mixed-integer linear programming (MILP) optimization 249 techniques. The objective functions for the strategy 1 and strategy 2 for continuous run and 250 power sharing modes have been modeled as a linear function of microgrid's distributed sources 251 output power. Therefore, for strategy 1 and strategy 2, the optimization problem is solved using 252 the linear programming (LP) solver "linprog" in MATLAB, which can be expressed as:

$$
\min _{x} f^{T} \text { obj subjected to }\left\{\begin{array}{c}
A \cdot x \leq b \\
\text { Aeq. } x=b e q \\
l b \leq x \leq u b
\end{array}\right\}
$$

254 where: $f, x, b, b e q, l b$ and $u b$ are vectors; $A$ and $A e q$ are matrices. 
255 The objective function for strategy 3 has been modeled as a mixed integer linear function of the 256 microgrid's distributed sources output power, where the switching function for the fuel cell 257 generator in Eq.(8) is an integer. Therefore, the objective function is modeled as a mixed integer 258 linear programming (MILP). This MILP problem can be solved using MILP solver "intlinprog" 259 in MATLAB. The "intlinprog" finds minimum of a problem by considering the constraints 260 specified by,

$$
\min _{x} f^{T} \text { obj subjected to }\left\{\begin{array}{c}
x \text { (int con) } \\
A . x \leq b \\
A_{e q} \cdot x=b_{e q} \\
l_{b} \leq x \leq u_{b}
\end{array}\right\}
$$

262 where: $f, x$, intcon, $b$, beq, $l b$ and $u b$ are vectors; $A$ and $A e q$ are matrices.

263 The BES's energy capacity for the microgrid under the proposed mix-mode operating strategy is 264 solved using PSO. Simultaneously, the economic dispatches for three strategies are performed 265 using linear programming and mixed-integer linear programming optimization techniques. In 266 support of this, the flowchart of the proposed battery sizing method is presented in Fig.2. 


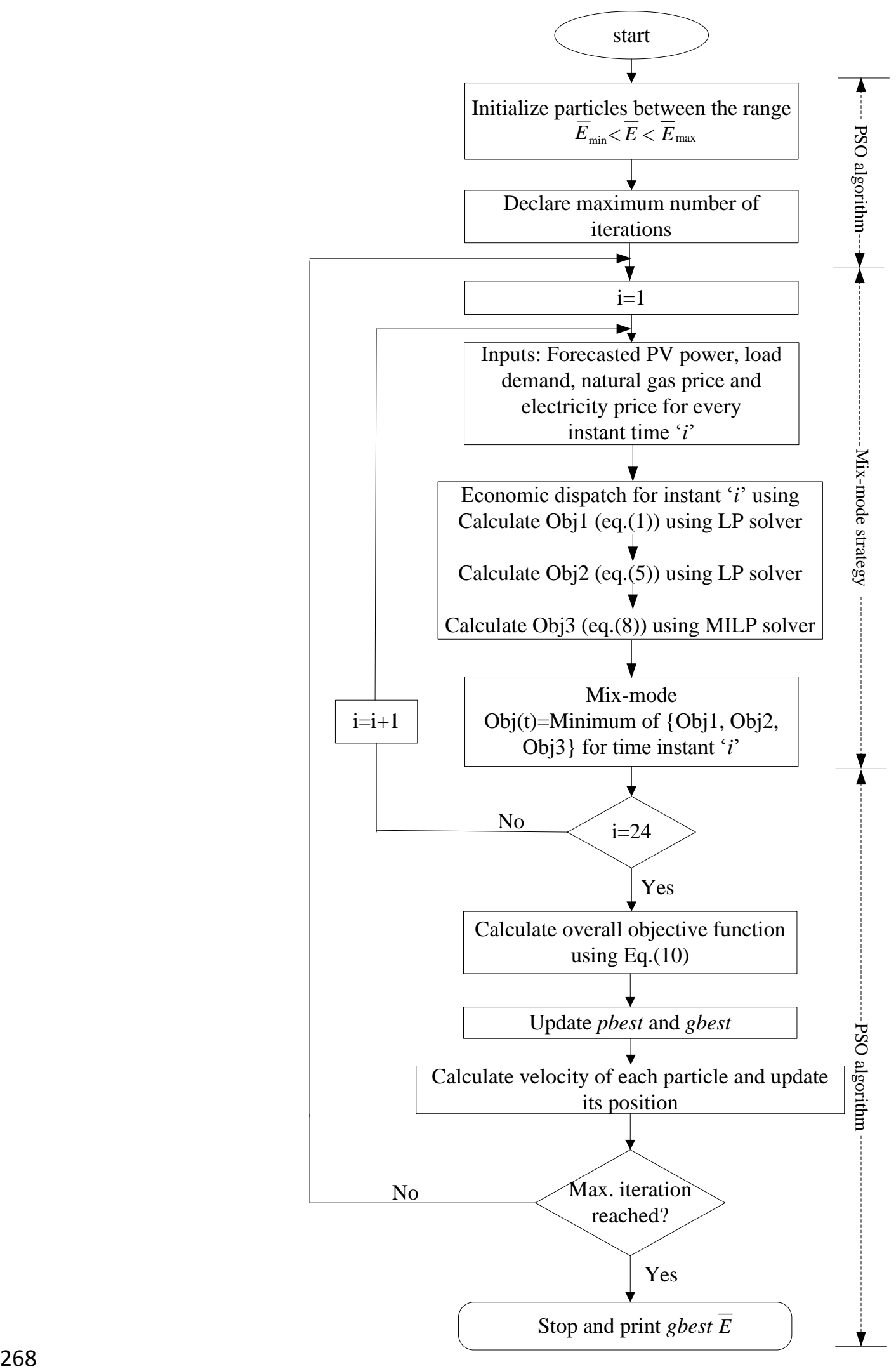


270 The proposed methodology is based on $24 \mathrm{~h}$ microgrid operation. To perform the sizing of battery

271 source, 24h data for the following variables are required: forecasted PV output power, load

272 demand, natural gas price and utility grid electricity price. As the first step in the proposed

273 method, the particles between the range is declared to be,

$$
\bar{E}_{\text {min }}<\bar{E}<\bar{E}_{\text {max }}
$$

275 The value of $\bar{E}_{\text {min }}$ and $\bar{E}_{\text {max }}$ is set according to the microgrid's characteristics. In this paper, the 276 value of $\bar{E}_{\text {min }}$ and $\bar{E}_{\text {max }}$ is set as $100 \mathrm{kWh}$ and 3,000 kWh, respectively. It means that the search 277 space for PSO is between the range of [ $100 \mathrm{kWh}, 3,000 \mathrm{kWh}]$. The power capacity of the battery $278 \bar{P}$ is fixed to $100 \mathrm{~kW}$ in this paper. Initially, particles between the search ranges are generated 279 randomly. Then, for each particle, the economic dispatch is solved for every time instant ' $t$ ' for 280 the three proposed operating strategies. The operational constraint for the battery source, fuel 281 cell, and utility grid is considered while solving the economic dispatch problem. From the three 282 solved objective function for time instant ' $t$ ', the lowest objective function is selected and 283 explained in Section 2.2. This procedure is repeated for the $24 \mathrm{~h}$ time period. Then the objective 284 function $(O b j)$ for a $24 \mathrm{~h}$ time period solved using mix-mode strategy is summed with the $285 T C P D_{B A T}$ to obtain the overall cost function. This procedure is repeated for all of the particles. 286 Once the objective functions for all the particles are evaluated, the particles personal best (pbest) 287 and global best (gbest) is updated. Then, the velocity of each particle is updated, and based on 288 the velocity, the new position of the particles is obtained. Thus, the whole process is repeated 289 until the maximum number of iterations is reached. When the number of iteration reaches its maximum, the system prints the optimal value of BES capacity $\bar{E}$ in kWh. 


\section{Case studies and results discussion}

294 To assess the validity of the proposed mix-mode energy management strategy and the proposed 295 battery sizing method, a low voltage grid connected microgrid shown in Fig. 3 is considered. The 296 grid connected microgrid consists of $200 \mathrm{~kW}$ solar PV, two identical $100 \mathrm{~kW}$ solid oxide fuel 297 cell, and a battery bank operated parallel with the load. The minimum and maximum operating 298 range of the single fuel cell unit is fixed as $10 \mathrm{~kW}$ and $100 \mathrm{~kW}$, respectively. Operating outside 299 the operating range will reduce the fuel cell's life [18]. The technical specification considered for modeling solid oxide fuel cell is taken from [19]. Utility grid electricity pricing and natural gas 301 pricing is shown in Fig.4 and is obtained from [20]. The forecasted PV output power and load 302 demand for $24 \mathrm{~h}$ time horizon is considered for this work. The microgrid uses lead-acid battery, 303 while the specific costs associated with the BES's power capacity $\left(C_{P}\right)$ and energy capacity $\left(C_{E}\right)$ 304 are set as $\$ 234 / \mathrm{kW}$ and $\$ 167 / \mathrm{kWh}$, respectively [15]. The battery lifetime and interest rate for 305 financing the battery source are set as 3 yrs and 6\%, respectively. The charging and discharge 306 efficiency are same and are set to $95 \% . P_{B A T, \min }$ and $P_{B A T, \max }$ of the battery is set as $-100 \mathrm{~kW}$ and $100 \mathrm{~kW}$, respectively. The minimum and maximum level of SOC for the battery should be

311 As a first step the superiority of the proposed mix-mode operating strategy in reducing the 312 overall microgrid's operating cost for a particular battery capacity is presented. Then, the 313 proposed battery sizing method is validated by comparing it to the trade-off method. The 314 variation of the optimal battery sizes for different battery's initial SOC levels is presented. With 315 this, an analysis on variation in microgrid's operating cost is also carried out. 


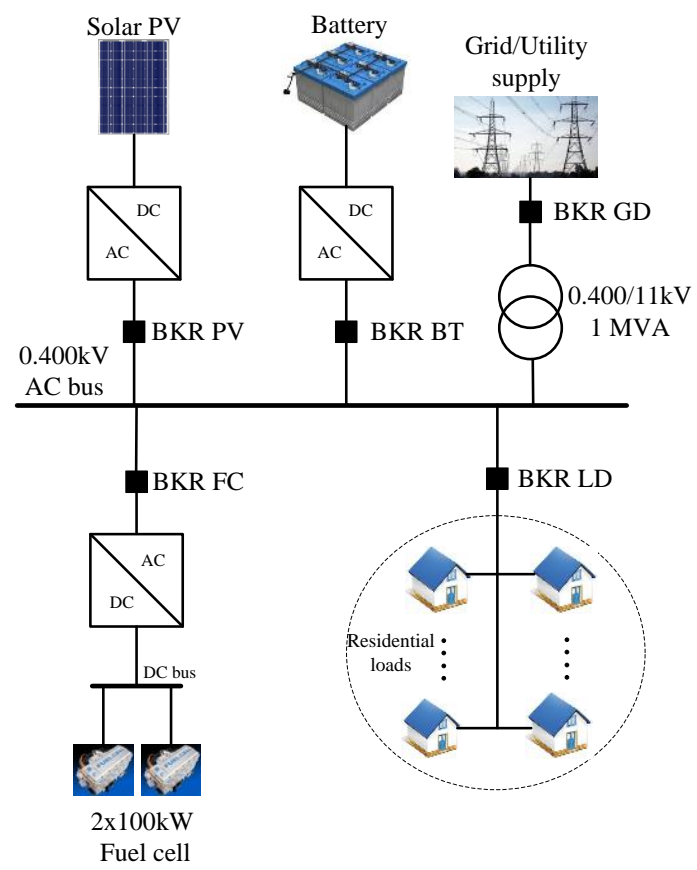

Fig.3 Microgrid test system

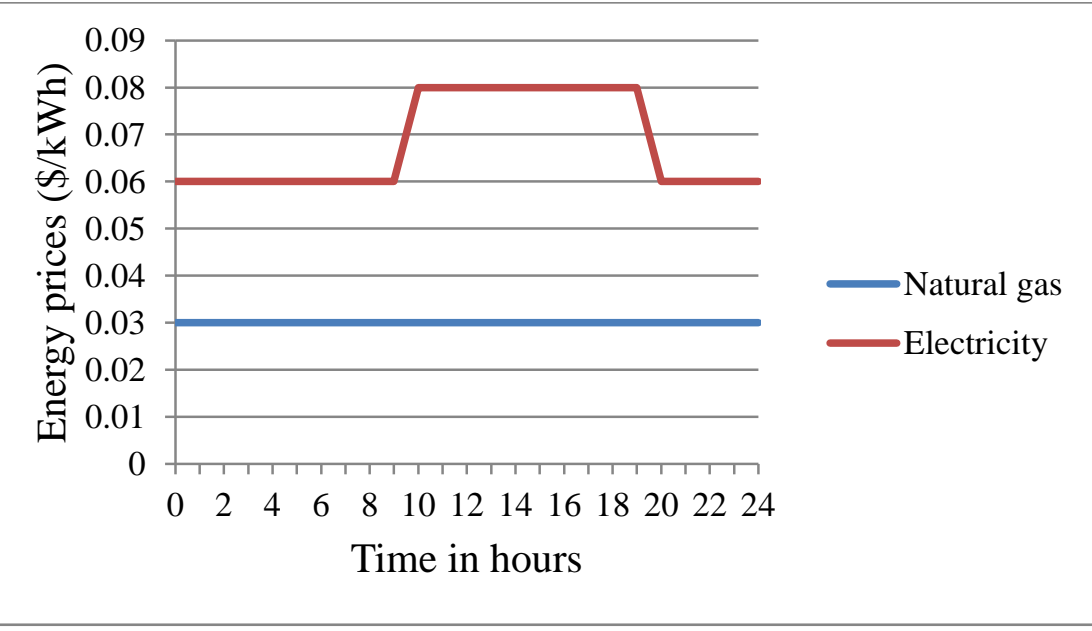

Fig.4. Utility energy prices in $(\$ / \mathrm{kWh})$

321

322 


\subsection{Comparison of the proposed mix-mode operating strategy with other operating} strategies

326 In this section, the superiority of the proposed mix-mode energy management strategy is

327 validated for the microgrid model presented in Fig. 3. In this study, since the battery source is 328 considered, the optimal size of the battery is determined using the proposed sizing method. The 329 initial SOC level of the battery during the start of the day is kept at $90 \%$. The battery size is 330 optimized within the range $[100 \mathrm{kWh}, 3,000 \mathrm{kWh}]$, considering all the battery and distributed 331 sources constraint. The optimal battery capacity for this case is found to be $2,497.6 \mathrm{kWh}$. The 332 results of the optimal dispatch values for the distributed sources in the microgrid for mix-mode 333 strategy are presented in Fig. 5. Fig. 6 show the battery state of charge (SOC) level maintained 334 within its limit.

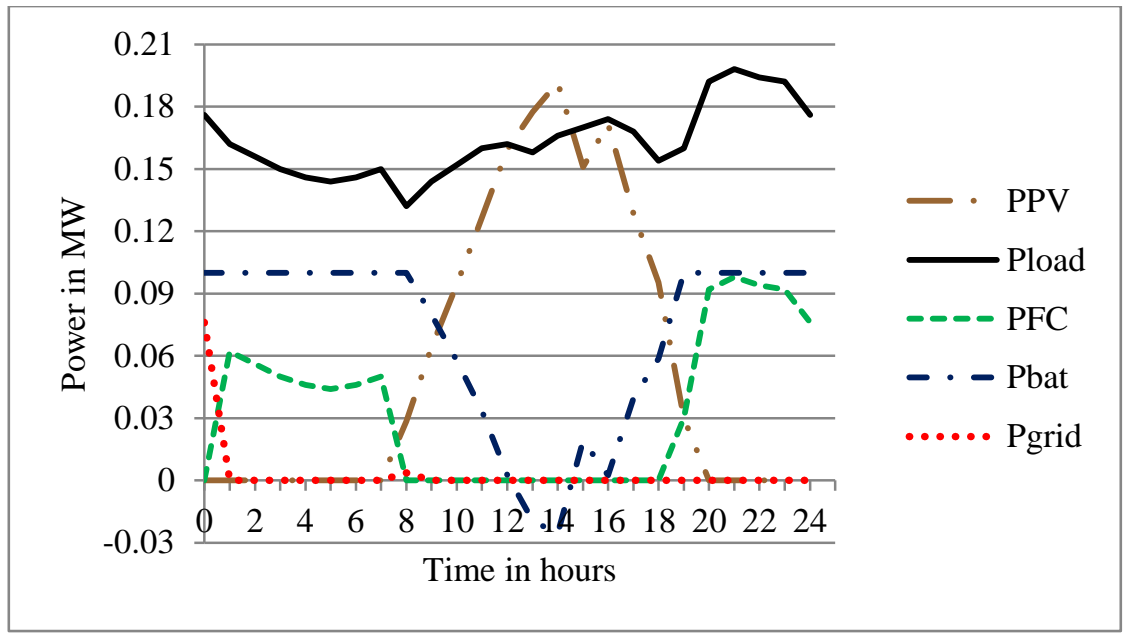




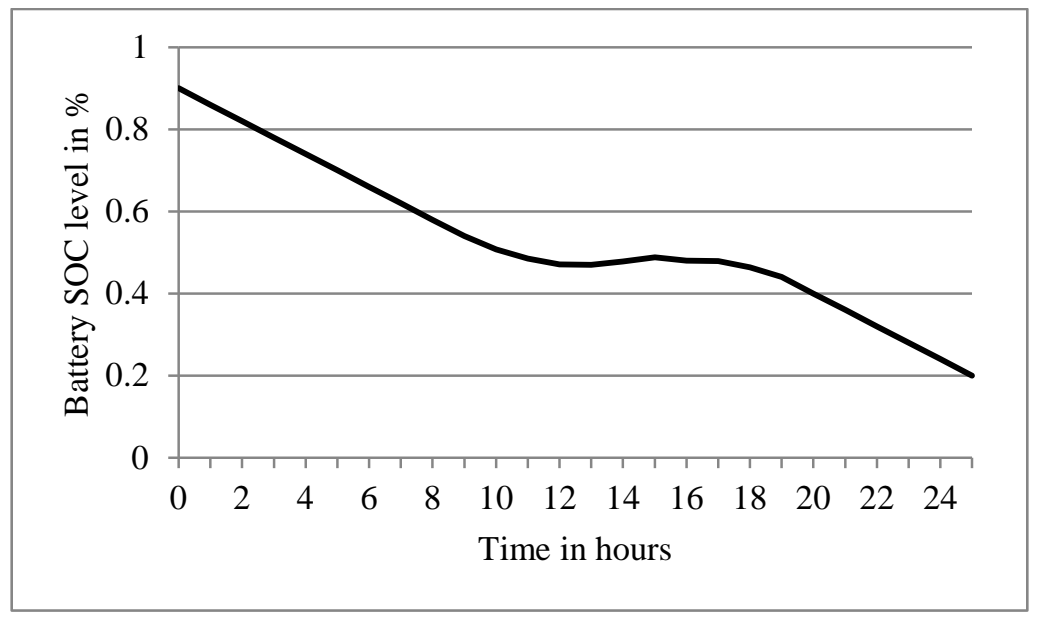

Fig.6. Battery SOC level for mix-mode operating strategy

A comparison on the daily operating cost for the proposed mix-mode strategy with other 342 strategies is tabulated in Table 1.

Table 1 Comparison of daily operating cost

\begin{tabular}{l|c|c|c|c}
\hline & $\begin{array}{c}\text { Strategy 1: } \\
\text { Continuous } \\
\text { run mode }\end{array}$ & $\begin{array}{c}\text { Strategy 2: } \\
\text { Power sharing } \\
\text { mode }\end{array}$ & $\begin{array}{c}\text { Strategy 3: } \\
\text { ON/OFF } \\
\text { mode }\end{array}$ & Mix-mode \\
\hline $\begin{array}{l}\text { Operating } \\
\text { cost in \$ }\end{array}$ & $1,880.8$ & $1,003.5$ & $1,073.6$ & 978.8768 \\
\hline $\begin{array}{l}\text { FC } \\
\text { operating } \\
\text { hours }\end{array}$ & 24 & 14 & 4 & 13 \\
\hline $\begin{array}{l}\text { Grid } \\
\text { operating } \\
\text { hours }\end{array}$ & 0 & 1 & 11 & 2 \\
\hline
\end{tabular}

344

The results from Table 1 shows that operating the microgrid in continuous run mode is more expensive. The fuel cell is also forced to run for the $24 \mathrm{~h}$ time period. The operating cost of microgrid is found to be less when the microgrid is operated under the power sharing mode when compared to the ON/OFF mode. However, the fuel cell is operated for $14 \mathrm{~h}$, which exceeded the ON/OFF mode where the fuel cell is forced to run at its rated capacity for only $4 \mathrm{~h}$. The 
350 advantage of operating the microgrid in the ON/OFF mode is that, when the fuel cell is forced to

351 run at the ON/OFF mode, the excess power can be used to charge the battery source. Moreover,

352 the run time of fuel cell is less during the ON/OFF mode, which will increase its calendar life.

353 The overall operating cost of the microgrid for the proposed mix-mode operating strategy is less

354 than other operating strategies. This proves that operating a microgrid in different operating

355 strategies for $24 \mathrm{~h}$ time period will incur the lowest operating cost.

$356 \quad 5.2$ Validation of the proposed battery sizing method

357 In this section, the validation of the proposed battery sizing method is carried out. The proposed

358 battery sizing method is validated with the "trade-off" method. Trade-off method can be used to

359 find the approximate battery storage capacity in $\mathrm{kWh}$. For this purpose, the operating cost (OC)

360 of the microgrid, battery's TCPD, and sum of OC and TCPD cost is plotted for different values

361 of the battery's energy capacity. Since the minimum and maximum range of the battery energy

362 capacity for this work is $[100 \mathrm{kWh}, 3,000 \mathrm{kWh}]$, the $O C, T C P D_{B A T}$, and $\left(O C+T C P D_{B A T}\right)$ are

363 plotted in Fig.7 for different energy capacities between these ranges on regular intervals. Fig. 7 is

364 plotted by taking into account the initial charge of the battery being equal to $100 \%$ of the battery

365 capacity, which is the initial SOC level of the battery during the start of the day taken as $100 \%$ in

366 this case. 


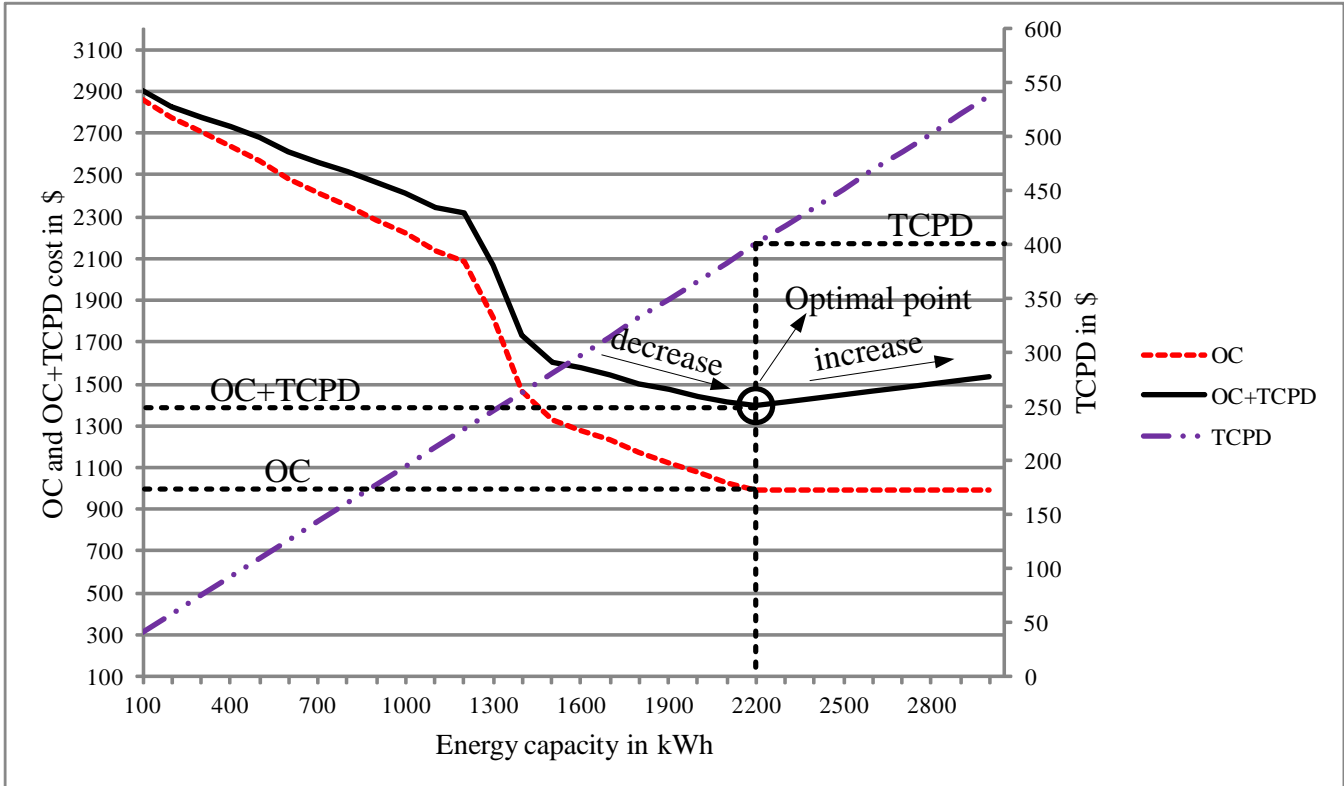

Fig.7 Optimal value of energy capacity in kWh using trade-off method

The operating cost (OC) of the microgrid is very high for lower battery capacities. As the battery capacity increases, the $\mathrm{OC}$ of the microgrid decreases. This is due to the availability of sufficient battery source for an economical microgrid operation. On the other hand, as the battery capacity increases, the battery's TCPD cost also increases. This is because the TCPD of the battery is directly associated with battery's installation cost. Therefore, with an increase in the battery capacity starting from $100 \mathrm{kWh}$, the sum of operating cost (OC) and battery's TCPD, which is the combined cost of $O C$ and $T C P D$, tend to decrease. With the increase in battery capacity at one point, the $\mathrm{OC}$ of the microgrid attains a minimum value, from where it does not decrease and remains constant for further increment in battery capacity. In this instant, the readers can notice a sudden change from a decreasing to an increasing trend in the combined cost of $O C$ and $T C P D$ costs. The point where a sudden change in the trend happens to be the optimal point, where the combined cost OC+TCPD is quite less. The point where the combined cost of OC and TCPD is less is encircled in Fig. 7, for which the corresponding battery capacity is found to be 2,200 $\mathrm{kWh}$. Here, the optimal battery capacity is obtained by a trade-off between microgrid's OC and 
383 battery's TCPD costs. The approximate operating cost (OC) of the microgrid for the optimal 384 value is plotted, and it is found to be $\$ 1,000$, while the TCPD cost associated with the battery is 385 approximately $\$ 400$. Therefore, the total combined cost of OC and TCPD from the Fig. 7 is 386 closer to $\$ 1,400$ per day. That is the point encircled in Fig.7, where it is closer to $\$ 1,400$ per 387 day. It can be noted from Fig. 7 that further increase in battery capacity beyond the 2,200 kWh 388 increases the combined cost of OC and TCPD, which is due to the increase in battery's TCPD 389 cost. On the other hand, it can be noticed that the OC of the microgrid remains constant for 390 further increase in battery capacity beyond 2,200 kWh. Choosing any value below 2,200 kWh 391 will increase the microgrid's operating cost.

392 In this paper, we propose an accurate method to determine optimal battery size using the PSO 393 optimization technique necessary for economic operation of microgrid. The microgrid is 394 operated in a mix-mode operating strategy. In this case, the battery size and operating cost of the 395 microgrid are simultaneously optimized. The battery capacity is optimized by considering the 396 initial SOC level during start of the day as $100 \%$. The optimal value of battery capacity 397 optimized using PSO is found to be 2,185.4 kWh. Table 2 provides a comparison between the 398 optimal value of battery capacity obtained using the trade-off method and the proposed sizing 399 method. In the table, the OC, TCPD and OC+TCPD costs obtained from the proposed sizing 400 method is compared with the trade-off method. The capacity of the battery and costs tabulated 401 for the proposed sizing method is very close to the values obtained using the trade-off method. 402 From the table, it is clear that the proposed battery sizing method is accurate enough to calculate 403 the battery capacity in kWh for the economic operation of the microgrid. 
method

\begin{tabular}{l|c|c}
\hline & Trade-off method & Proposed sizing method \\
\hline Optimal battery capacity $(\mathrm{kWh})$ & 2,200 & $2,185.4$ \\
\hline OC $(\$)$ & 1,000 & 978.8768 \\
\hline TCPD $(\$)$ & 400 & 398.0547 \\
\hline OC+TCPD $(\$)$ & 1,400 & $1,376.9315$ \\
\hline
\end{tabular}

407

408

409

410

411

412

413

414

415

416

417 The optimal values of the BES are found to be 2,185.4 kWh, 2,497.6 kWh and 2,913.9 $\mathrm{kWh}$

418

419

420

421

422

423

424

425

\subsection{Analysis of variation in optimal energy capacity of battery source for initial SOC levels} $100 \%, 90 \%$ and $80 \%$ during start of the day

The main advantage of adding battery source in the microgrid is to maintain stability, improve power quality, and facilitate the integration of renewable sources [21-24]. In this case, the optimal battery capacity required for the economic microgrid operation is evaluated by considering the initial SOC of the lead acid battery to be $100 \%, 90 \%$, and $80 \%$ during the start of the day. Therefore, the optimal battery capacity $\bar{E}$ for each of the initial SOC level is optimized within the range [100 kWh , 3,000 kWh] using the proposed battery sizing method. when the battery initial SOC levels are $100 \%, 90 \%$ and $80 \%$ respectively during the start of the day. This is validated using the trade-off method by plotting various costs against different battery capacity ranging between $[100 \mathrm{kWh}, 3,000 \mathrm{kWh}]$.

The results for the optimal energy capacity using the trade-off method when the microgrid is operated under mix-mode strategy, considering the battery source with initial SOC levels as $100 \%, 90 \%$ and $80 \%$ during the start of the day are presented in Fig. 8 . The optimal values are attained for the lowest value of combined cost of OC and TCPD is found to be 2,200 kWh, 2,500 $\mathrm{kWh}$ and 2,900 kWh for initial SOC cases of 100\%, 90\%, and $80 \%$ respectively. 


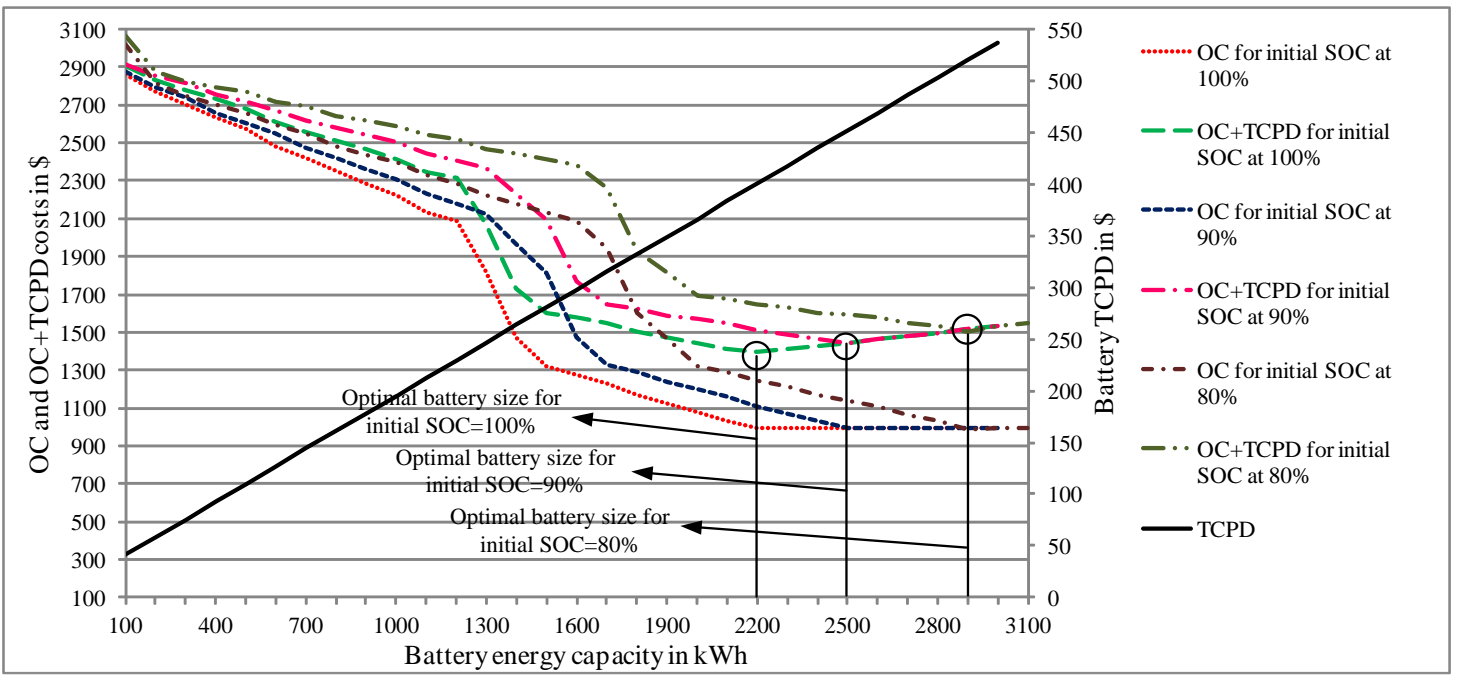

427 Fig. 8. Optimal value of energy capacity in kWh using trade-off method for initial battery SOC at $100 \%, 90 \%$ and $80 \%$

429 From Fig.8, it can be noted that the microgrid's operating cost (OC) and the combined cost of 430 OC and TCPD is not same when the battery source initial SOC levels during start of the day are $431100 \%, 90 \%$ and $80 \%$. The OC and combined cost of OC and TCPD is very much decreased 432 when the battery initial SOC level during the start of the day is $100 \%$. In other words, if the 433 battery's initial SOC level is very large, the operating cost of the microgrid is reduced to its 434 lowest value. Fig.8 shows that the operating cost of the microgrid settles to a constant value of 435 the battery's optimal capacity value. For example, in the case of the battery initial SOC level $436100 \%$, the operating cost settles at an approximate value of $\$ 1,000$ at 2,200 $\mathrm{kWh}$. Similarly, for 437 cases of initial SOC levels at $90 \%$ and $80 \%$, the operating cost settles down to a constant value 438 of $\$ 1,000$ at optimal values of $2,500 \mathrm{kWh}$ and $2,900 \mathrm{kWh}$, respectively. A clear comparison 439 between the optimal values obtained for different battery initial SOC levels for the trade-off method and the proposed sizing method is presented in Table 3. 
443 Table 3. Comparison of optimal value obtained using trade-off method and proposed sizing 444 method for battery initial SOC levels $100 \%, 90 \%$ and $80 \%$

\begin{tabular}{l|c|c|c|c|c|c}
\hline & \multicolumn{3}{|c|}{ Trade-off method } & \multicolumn{3}{c}{ Proposed sizing method } \\
\hline Initial SOC at & $100 \%$ & $90 \%$ & $80 \%$ & $100 \%$ & $90 \%$ & $80 \%$ \\
\hline $\begin{array}{l}\text { Optimal battery } \\
\text { capacity (kWh) }\end{array}$ & 2,200 & 2,500 & 2,900 & $2,185.4$ & $2,497.6$ & $2,913.9$ \\
\hline OC in \$ & 1,000 & 1,000 & 1,000 & 978.8768 & 978.8768 & 978.8768 \\
\hline TCPD in \$ & 400 & 450 & 520 & 398.0547 & 451.4934 & 522.7506 \\
\hline OC+TCPD in \$ & 1,400 & 1,450 & 1,520 & $1,376.9315$ & $1,430.3702$ & $1,501.6274$ \\
\hline
\end{tabular}

Table 3 show that with decreasing levels of the battery's initial SOC level during the start of the

447

448

449

450

451

452

453

454

455

456

457 458 of the day. day, the battery's optimal capacity increases. Therefore, in order to reduce the microgrid's operating cost to its lowest value with less battery initial cost, it is suggested that the optimal battery capacity with higher initial SOC be used during the start of the day. This will reduce the microgrid's operating cost with less battery initial cost.

\subsection{Analysis of variation of microgrid's operating cost for different initial SOC levels}

\section{during start of the day}

This section will analyze the variation in the microgrid's operating cost for different initial SOC levels during the start of the day. Prior to the analysis, it is necessary that the microgrid's operating cost in the absence of battery energy storage, be evaluated. Hence, this section is divided into two sub-sections, (i) microgrid operation without battery source, and (ii) microgrid operation with battery source having initial SOC levels at $100 \%, 70 \%$, and $50 \%$ during the start

\section{$459 \quad$ 5.4.1 Microgrid operation without battery energy storage}

460 This section discusses the operation of grid connected microgrid without battery source. All the 461 distributed sources present in the microgrid, including utility grid, should satisfy the forecasted 462 load demand for the $24 \mathrm{~h}$ time period. In this case, there may be instances where the output power 
463 from the PV may exceed the load demand. Since the battery source is unavailable for charging 464 the excess power, a load resistor is modeled to ground the excess power. By load demand and 465 maximum available power from the distributed sources, the results for the microgrid operation 466 for mix-mode are presented in Fig. 9.

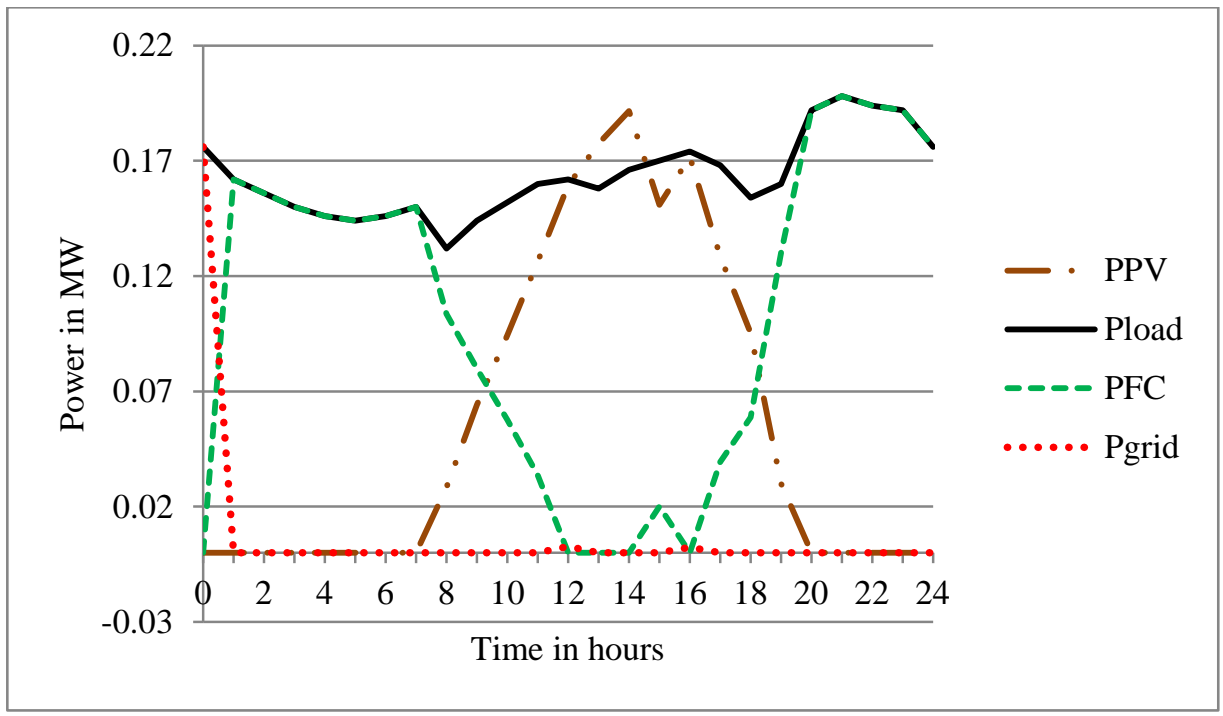

Fig.9 Optimal operation of microgrid without battery source source available to deliver ancillary service, the maximum available power from the fuel cell and utility grid is drawn by the load. This forces the fuel cell to extend its operating hours by $20 \mathrm{~h}$. Overall, since no battery is employed, the microgrid rely on power from the fuel cell and the utility grid. Furthermore, the fuel cell operating hours exceeds that of the utility grid operating hours. This is because the power drawn from the fuel cell is cheaper than power purchased from the utility grid. There are instances where utility grid is scheduled instead of the fuel cell. During the entire $24 \mathrm{~h}$ operating time, the utility grid is optimally scheduled for $3 \mathrm{~h}$. 


\subsubsection{Microgrid operation with battery source having initial SOC levels at $100 \%, 70 \%$ and}

\section{$50 \%$ during start of the day}

The lead-acid battery is added to the microgrid test system for this case study. During the early morning hours, since the battery source is cheap, it will effectively be used to supply the varying load. There is no chance of the battery charging during the early morning hours that is before the sun-rise. Keeping the initial battery cost in mind, the initial SOC of the battery during the start of the day is set to $100 \%$. The results in Fig. 10 portray the optimal dispatch values of the distributed sources in the microgrid when the battery initial SOC level is $100 \%$ during the start of the day. The optimal battery capacity for this case is found to be 2,185.4 kWh. During the early morning hours that is before the sun-rise, the power to the load is managed by battery, fuel cell, and the utility grid. During the day, when PV power is present, the battery source is efficiently managed to supply the load or charge when PV power exceeds the load demand. During this period of operation, the power from the fuel cell and utility grid are quite low, or in some cases zero for the majority of the time period. This is due to the availability of cheaper battery power. During the evening hours along the side of battery source the fuel cell is also used to supply the load. The power drawn from the utility grid is zero during this time, because the power purchase cost from the utility grid is very high than the cost of power drawn from battery source and fuel cell. From Fig. 11, it is clear that the battery SOC level is kept within the limits. 


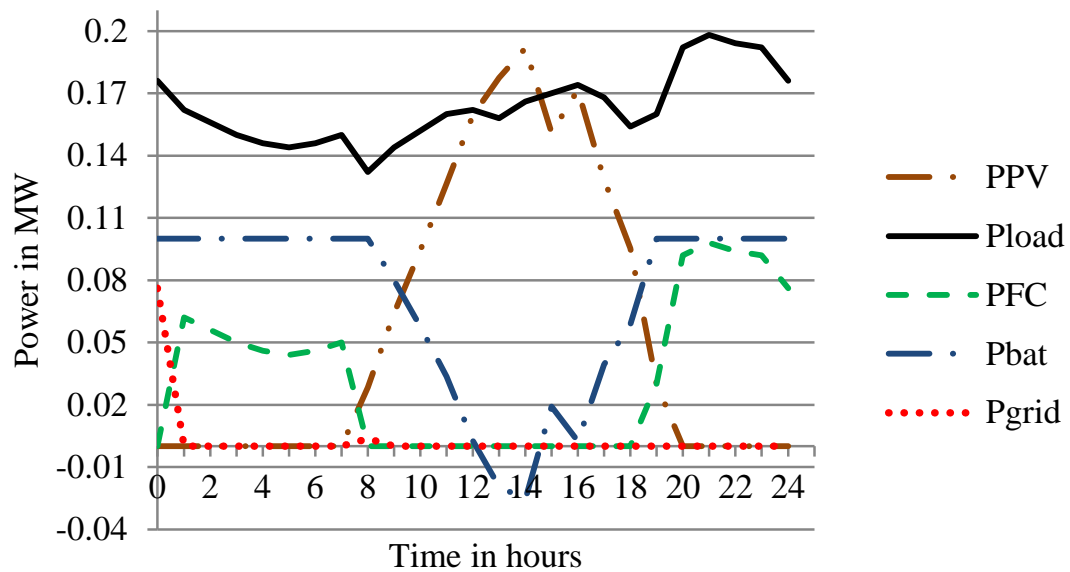

Fig.10 Optimal output of distributed source in microgrid for when battery initial SOC at $100 \%$ of

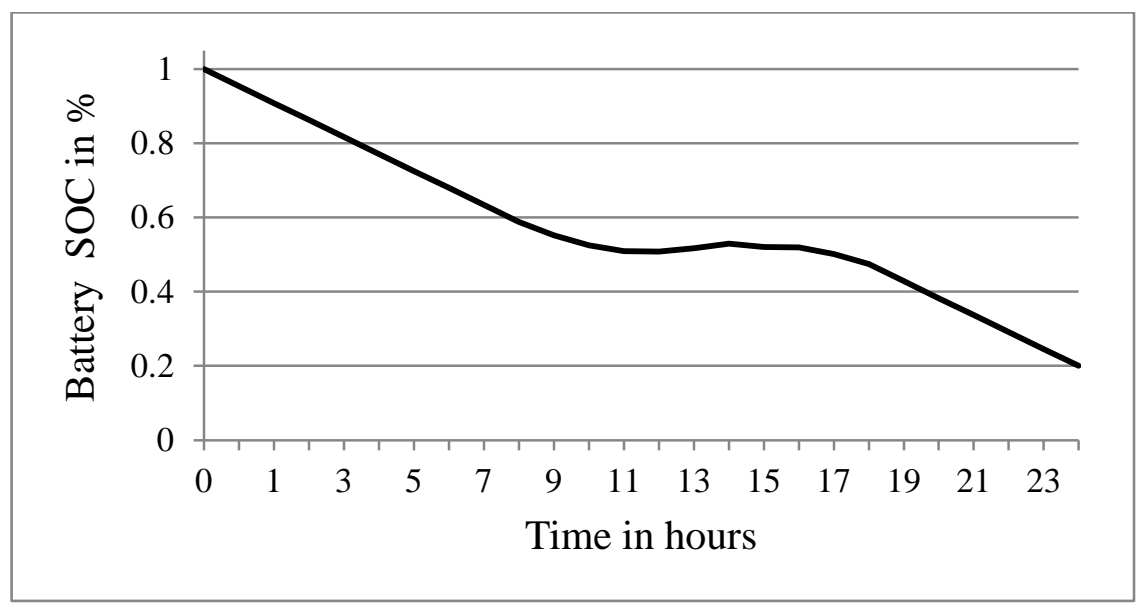

Fig.11. Battery SOC level for mix-mode operating strategy when battery initial SOC at $100 \%$ of

503 A battery size of $2,185.4 \mathrm{kWh}$ is the optimal capacity when the initial SOC is at $100 \%$ during the 504 start of the day. It is our interest to set the initial SOC level to $70 \%$ and $50 \%$ during the start of 505 the day for the battery size of $2,185.4 \mathrm{kWh}$ and observe the operation of the microgrid and 506 calculate its operating cost. Fig. 12 and Fig.13 shows the optimal dispatch values and battery 507 SOC level when the battery initial SOC level is set to $70 \%$ of $2,185.4 \mathrm{kWh}$ during the start of the 
day. Similarly, Fig.14 and Fig15 shows the optimal dispatch values and battery SOC level when the battery initial SOC level is set to $50 \%$ of $2,185.4 \mathrm{kWh}$ during start of the day.

The discharging action of battery in each time step of the day is restricted to how much it charges in previous hours. It can be noticed from Fig.10, Fig.12 and Fig.14 that when the initial SOC is high during the start of the day the battery operates for longer hours. On the other hand, when the initial SOC level of the battery is set low, the battery operating hours is less due to the scarcity of charge in the battery source. When the initial SOC is $70 \%$ in Fig. 12, the battery operating hours is found to be less, and the battery is completely switched OFF during the night hours. Similarly, when initial SOC is 50\% in Fig.14, the battery is switched OFF during night hours and even for few hours during the day-time. For cases of lower initial SOC levels, particularly during night hours, the second unit of the fuel cell is switched ON to supply power to varying load, since the power drawn from utility grid is more expensive. A brief comparison of the microgrid's operating cost without and with battery source with different initial SOC levels are presented in Table.4. The operating cost of the microgrid without battery source is determined to be $\$ 3,332 /$ day. The microgrid operating cost with optimal battery source of $2,185.4 \mathrm{kWh}$ having an initial SOC at $100 \%$ at the start of the day is $\$ 978.8768 /$ day. This means that operating the microgrid with optimal battery sizing reduces the overall operating cost by $70 \%$ for a single day. This is due to the availability of the battery source, and therefore, the battery operating hours is increased to $22 \mathrm{~h}$. On the other hand, with the same optimal battery size where the initial SOC is set at $70 \%$ during the start of the day, it will reduce the overall operating cost by only $55 \%$ for a single day. Moreover, this increases the fuel cell operating hours to $14 \mathrm{~h}$, and reduces the battery operating hours to $18 \mathrm{~h}$. For an initial SOC of $50 \%$ during the start of the day case, the operating cost of the microgrid is $\$ 2,335.3 /$ day, where the savings is only $30 \%$ for a single day, which is 
531 even lesser than the higher initial SOC cases. In this case, the fuel cell and utility grid operating

532 hours are increased to $18 \mathrm{~h}$ and $3 \mathrm{~h}$, respectively while the battery run time is reduced to $10 \mathrm{~h}$.

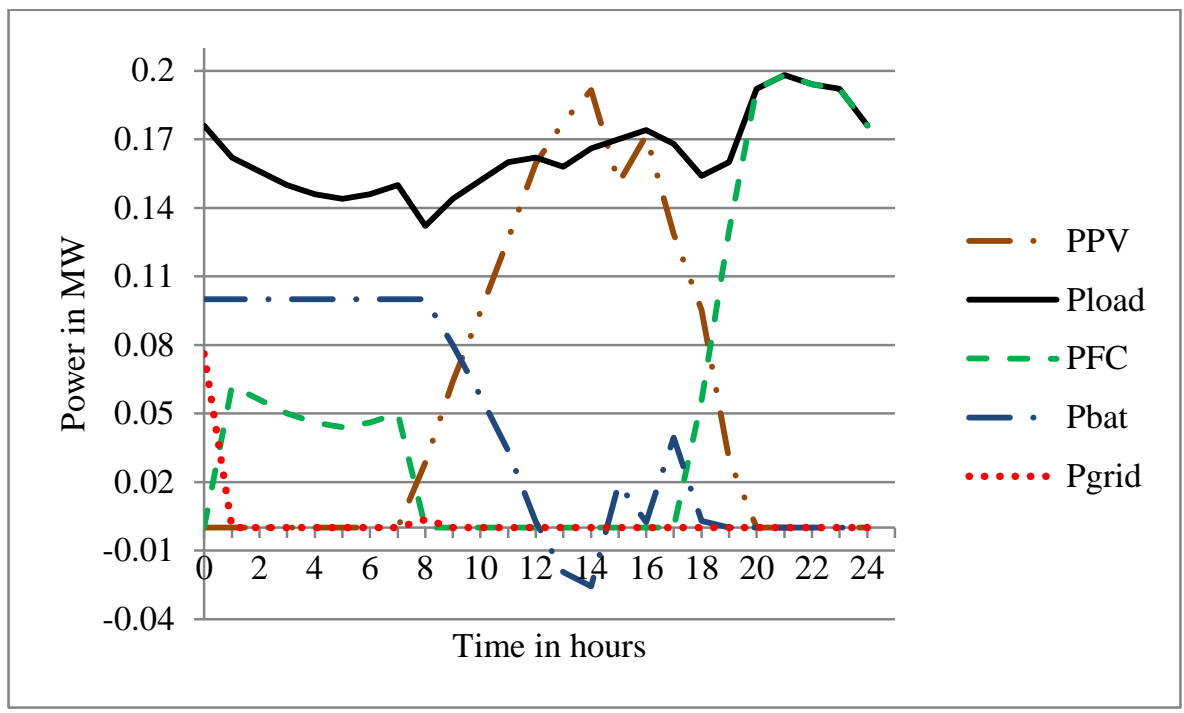

534 Fig.12 Optimal output of distributed source in microgrid for when battery initial SOC at $70 \%$ of

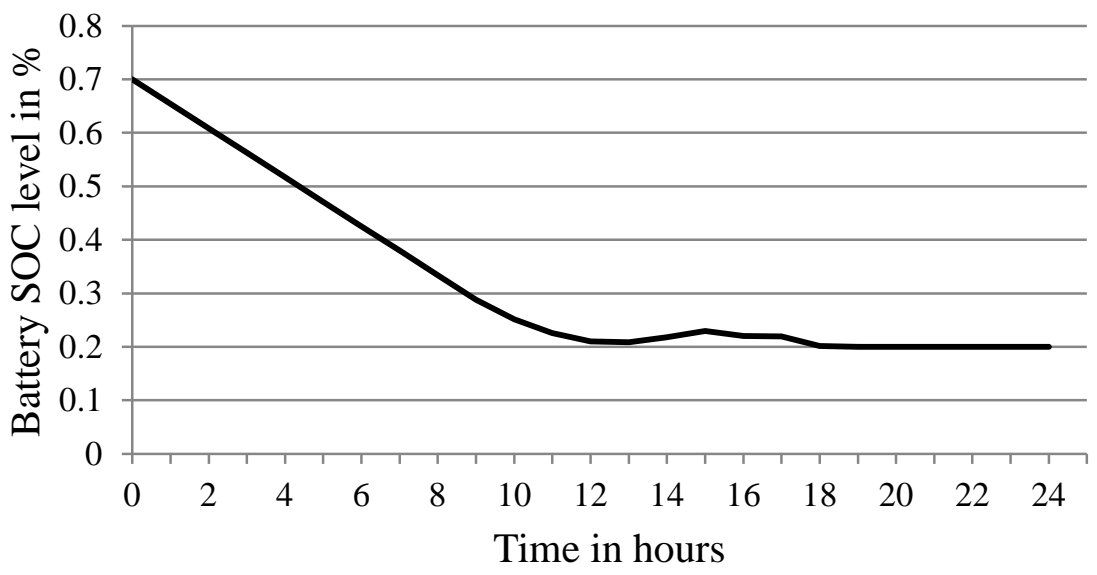

537 Fig.13. Battery SOC level for mix-mode operating strategy when battery initial SOC at $70 \%$ of 


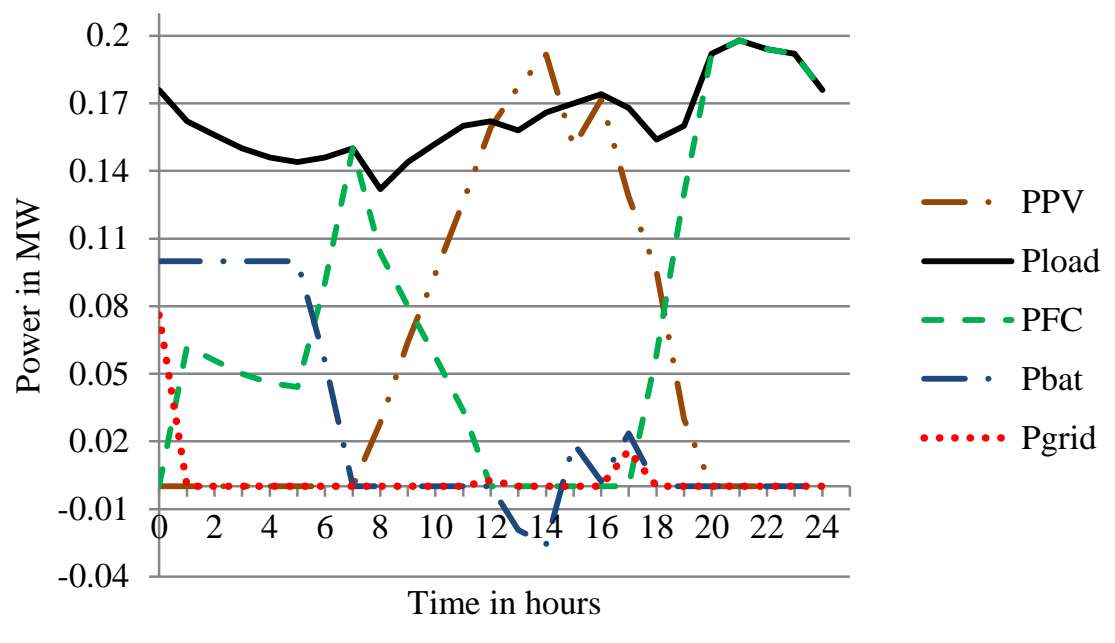

Fig.14 Optimal output of distributed source in microgrid for when battery initial SOC at $50 \%$ of

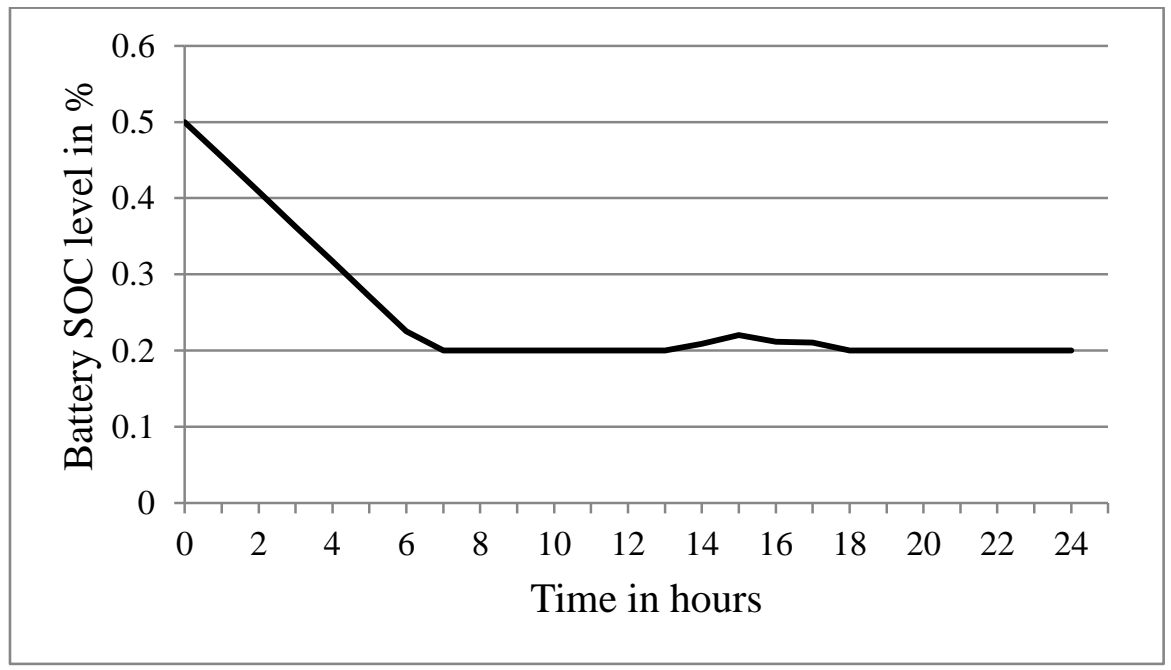

543 Fig.15. Battery SOC level for mix-mode operating strategy when battery initial SOC at $50 \%$ of 
Table 4. Comparison of operating cost with and without battery case.

\begin{tabular}{l|c|c|c|c}
\hline & \multicolumn{3}{|c|}{ With battery source } & $\begin{array}{c}\text { Without } \\
\text { battery source }\end{array}$ \\
\hline Optimal BES capacity (kWh) & \multicolumn{3}{|c|}{2185.4} & - \\
\hline Battery initial SOC level & $100 \%$ & $70 \%$ & $50 \%$ & - \\
\hline Operating cost in (\$/day) & 978.8768 & 1,491 & $2,335.3$ & 3,332 \\
\hline Fuel cell operating (hr) & 13 & 14 & 18 & 20 \\
\hline Grid operating (hr) & 2 & 2 & 3 & 3 \\
\hline Battery operating (hr) & 22 & 18 & 10 & - \\
\hline Savings in operating cost in \% & $70 \%$ & $55 \%$ & $30 \%$ & - \\
\hline
\end{tabular}

550

551

552

553

554

555

556

557 From the discussions, it can be concluded that,

558 559 reduce the its operating cost.

560

561

562

563

564

565

566

567

568 utility grid is very high. lowest battery’s capital cost. hours.

Table 4 shows that if the battery source is optimal with higher initial SOC during the start of the day, there is a significant reduction in microgrid's operating cost. Moreover, the fuel cell operating hours will also be reduced, which will increase its calendar life. During the microgrid mix-mode operation, the utility grid operating hours is lower as the power purchase cost from the

(i) Operating the microgrid under the proposed mix-mode operating strategy can effectively

(ii) Including battery source in the microgrid will reduce the daily operating cost.

(iii) Installing optimal battery capacity with higher initial SOC is highly recommended because the optimal battery capacity with higher initial SOC will reduce the daily operating cost with

64 (iv) Installing battery capacity with higher initial SOC reduces fuel cell and utility grid operating

66 There is no recommendation found in literature on settings of the initial battery SOC level for 67 microgrid operation. Based on the results depicted in Fig. 8 and Table 3 it is highly recommended 68 that the battery capacity with higher initial SOC be used during the start of the day. This will 
569 reduce the microgrid's operating cost with less battery capital cost, which is the battery's TCPD.

570 When there is no possibility of battery charging during the start of the day's operation, it is

571 highly recommended that the initial SOC of the battery be set to $100 \%$. If there are any possible

572 charging events, then the battery initial SOC can be set to $90 \%-95 \%$.

5735.5 Analysis on variation of microgrid's operating cost considering uncertainty in PV

574 output power

575 Output power from the solar PV plant is uncertain and relies on solar radiation, which is

576 intermittent in nature. As a result of this, considerable effect in microgrid's operating cost and

577 battery source operation can be found. Therefore, in this section an analysis on variation of

578 microgrid's operating cost and battery source operation is carried out for changes in the PV

579 output power. In this analysis, the energy capacity of the lead-acid battery source, evaluated in

580 Section 5.4.2 for the initial SOC level of 100\%, is considered. Hence, the energy capacity of the

581 battery source considered for this analysis is $2,185.4 \mathrm{kWh}$, and the initial SOC level during the

582 start of the day is set to $100 \%$ as recommended in Section 5.4.2.

583 The optimal battery capacity of $2,185.4 \mathrm{kWh}$ is evaluated for a particular PV output power

584 pattern. This analysis is carried out to study the variation of microgrid's operating cost and

585 battery source operation when the PV output power changes. Two PV output power patterns, (i)

586 PV output power from the solar plant during winter and (ii) PV output power from the solar plant

587 during summer are considered for the study.

588 Results in Fig.16 shows the optimal dispatch values of the distributed sources in the microgrid

589 for a day in winter, with its corresponding battery SOC level plotted in Fig.17. 


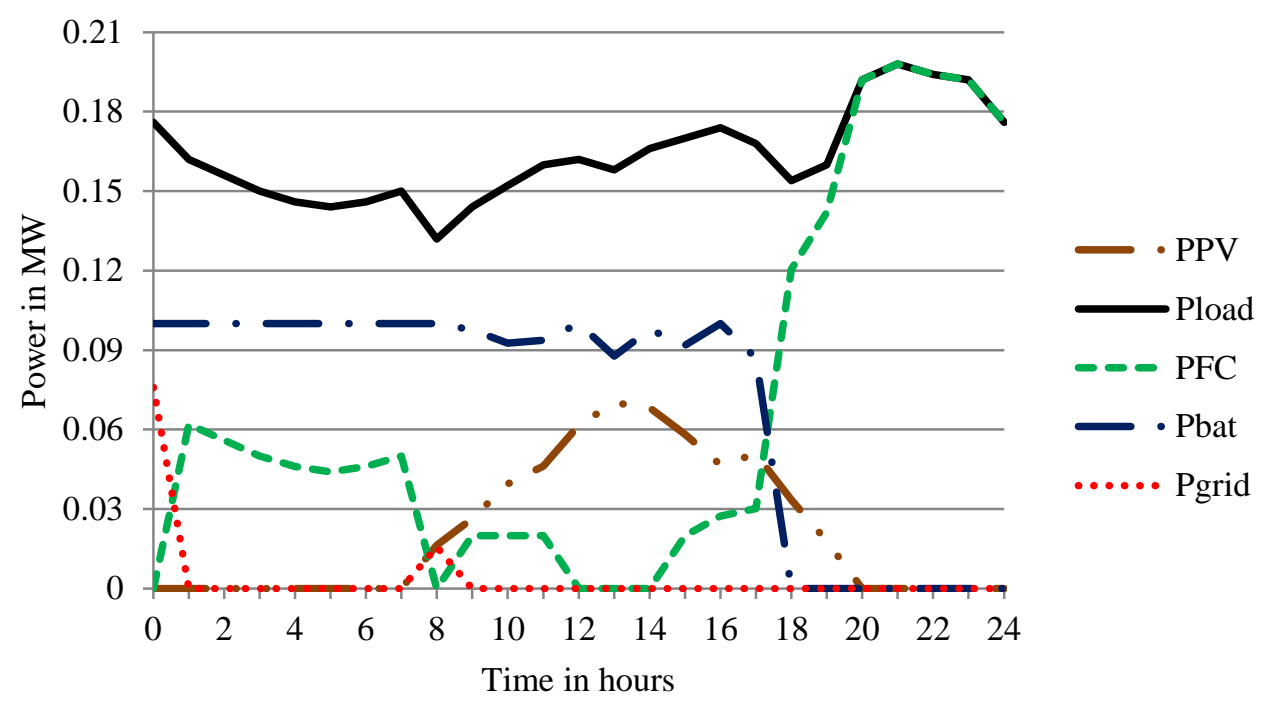

Fig.16 Optimal output of distributed source in microgrid during a day in winter

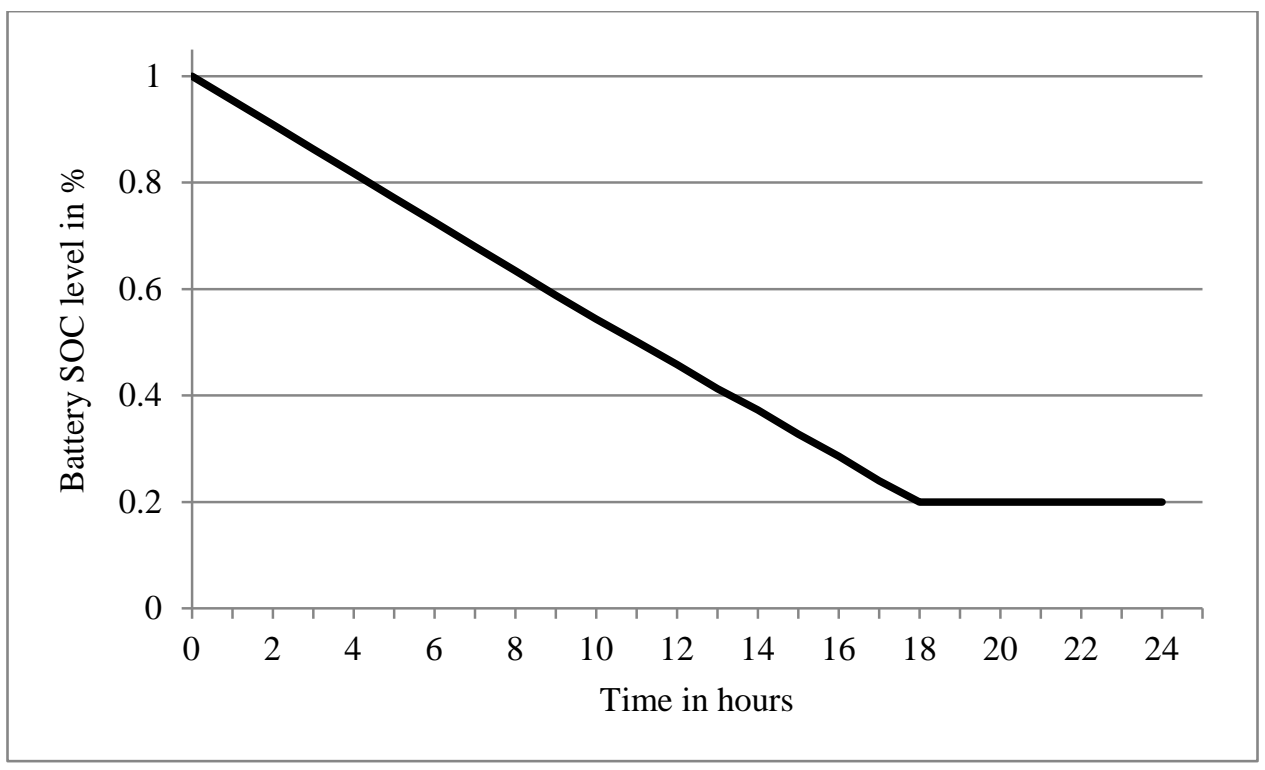

Fig.17 Battery SOC level for a day in winter

594 During the early morning hour that is before the sun-rise, the power to the load is managed by 595 the battery source, fuel cell, and the utility grid. The utility grid is utilized because the power 596 drawn from the utility grid is cheap in morning hours. During the day hours, the power to the 597 varying load is managed by PV output power, battery, and fuel cell. Since the PV output power 598 is less during the winter, the battery source is forced to discharge in-order to manage the load 
599 demand. It is also evident from Fig.16, that the fuel cell dispatches power for few hours during 600 the day to manage power to the load demand. During these hours, the power drawn from the 601 utility grid is kept at zero, considering its cost. Since the power from the battery is cheap, it is 602 utilized most of the time during the day, and since the PV output power is less than the load, 603 there are no battery charging instances. During evening hours, the battery power is unavailable 604 because the SOC level has reached its minimum level due to the fact that the battery source is 605 effectively utilized during the day hours. Therefore, during evening hours, fuel cell is effectively 606 utilized to supply power to varying load demand. As a result of this, both the fuel cell units are 607 switched ON to supply the varying load. The power from the utility grid is kept at zero due to the 608 cost of power produced from the fuel cell is being less compared to the power drawn from the 609 utility grid.

610 Fig.18 and Fig.19 are the optimal dispatch values of microgrid's sources and battery SOC level 611 for a day in summer respectively.

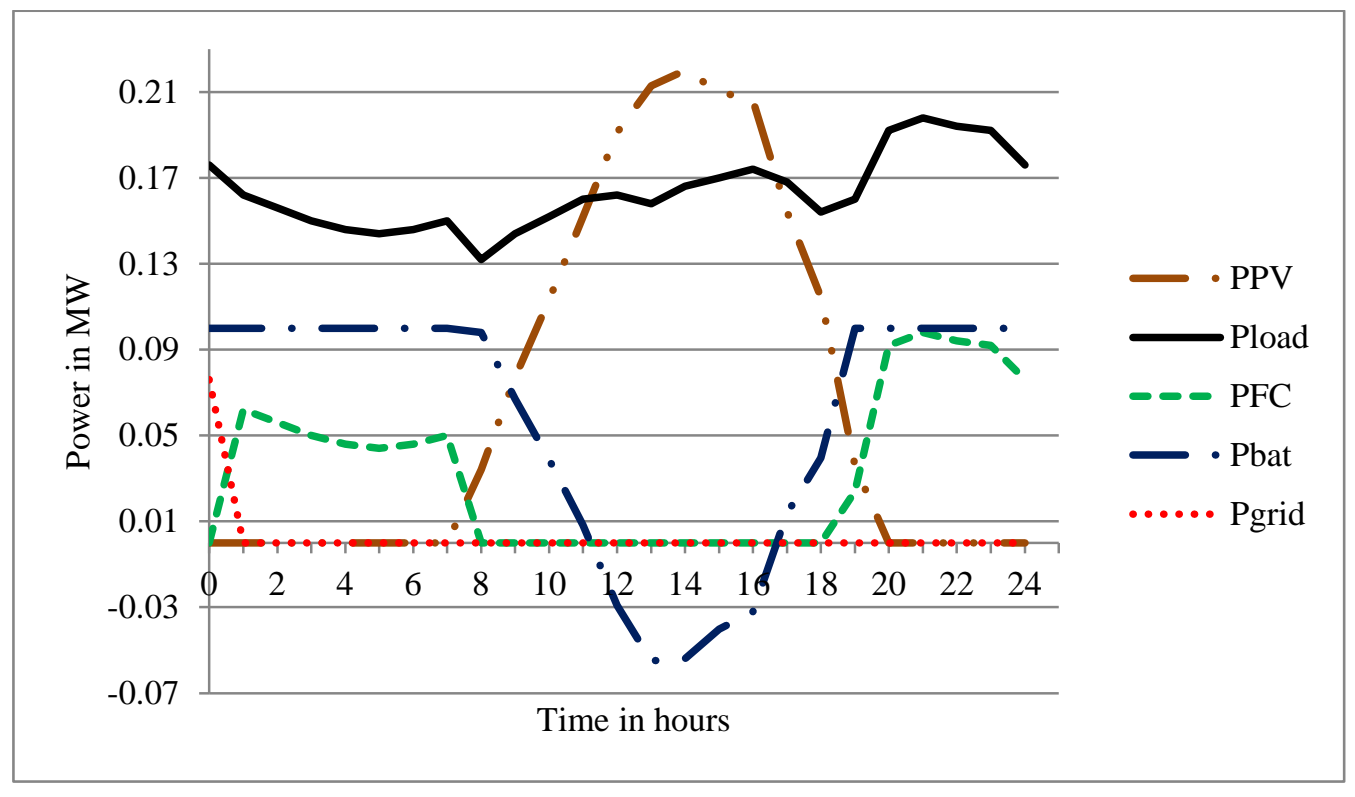

Fig.18 Optimal output of distributed source in microgrid during a day in summer 
614

615

616 During the early morning hours, the load demand is supplied by the power from utility grid,

617 battery source, and fuel cell. The utility grid is utilized because the power drawn from the utility

618 grid is cheap during the morning hours. During the day, when PV power is available, the battery source is effectively managed in order to supply power to the load demand. The power from the PV plant is high during the summer, and there are instances where the PV output power

621 exceeded the load demand. As a result of this, during these instances, the battery source operates 622 in the charging mode. During the day, since the availability of the PV power is high, the power 623 drawn from the utility grid and fuel cell is zero, and as a result of this, the fuel cell operating 624 hours is reduced. During the evening hours, the varying load demand is supplied by the battery 625 source and fuel cell. Since the battery source is charged for few hours during the day, it is 626 effectively utilized to supply power during the evening hours. As a result of this, only one fuel 627 cell unit is utilized to manage the load demand. During the evening hours, the power drawn from 628 the utility grid is zero. 


\begin{tabular}{l|c|c}
\hline Optimal BES capacity (kWh) & \multicolumn{2}{|c}{2185.4} \\
\hline Battery initial SOC level & \multicolumn{2}{|c}{$100 \%$} \\
\hline Operating cost in (\$/day) & $2,413.630$ & 925.510 \\
\hline Fuel cell operating (hr) & 20 & 13 \\
\hline Grid operating (hr) & 2 & 1 \\
\hline Battery operating (hr) & 17 & 20 \\
\hline
\end{tabular}

632

633

634

635

636

637

638

639

640

641

642

643

644

645

646

647

A comparison on microgrid's operating cost and microgrid sources operating hours are presented in Table 5 for a day for both winter and summer seasons.

Table 5. Comparison of microgrid's operating cost and microgrid sources operating hours

It can be noticed that the microgrid's operating cost is very much reduced during the day in the summer compared to winter. This is due to the availability of PV power during the day of summer. During the summer, the availability of PV output power is more and the large amount of load demand during the day hours is taken care of by the power from the PV plant. Simultaneously, there are instances of battery charging during the day time when the PV output power exceeded the load demand. As a result of this, the charged battery power is effectively utilized during the evening hours, which reduces the microgrid's operating cost for the day in summer. Due to this reason the battery operating hours is increased to $20 \mathrm{~h}$ during the day in summer. Since the battery power is available for longer hours, it eventually contributes to the reduction in utility grid and fuel cell operating hours, and the utility grid and fuel cell operates for $1 \mathrm{~h}$ and $13 \mathrm{~h}$, respectively, during the day in summer.

On the other hand, the output power from the PV plant is lesser during winter, and the battery source is effectively utilized during the day hours to supply power to the varying load demand. Since the power from the PV plant is lesser than the load demand, there are no charging instances for battery source. As a result of this, the battery source is unavailable during the evening hours. Therefore, the battery source's operating hours is reduced to $17 \mathrm{~h}$. In order to 
648 supply power to the load during the evening hours, both the units of fuel cell were forced to

649 supply power to the varying load demand. Since the availability of battery source is less in the

650 winter, the fuel cell and utility grid's operating hours increased to $20 \mathrm{~h}$ and $2 \mathrm{~h}$, respectively. As a 651 result of this, the microgrid's operating cost is increased to $\$ 2,413.63 /$ day during the day of the 652 winter.

\section{6. Conclusion}

654 In this paper, a mix-mode energy management strategy (MM-EMS) for operating the microgrid 655 at the lowest operating cost and optimal battery sizing method for economic microgrid operation 656 is presented. The mix-mode operating strategy is worked out by solving economic dispatch 657 problem for three proposed strategies, namely continuous run mode, power sharing mode, and 658 ON/OFF mode. Linear programming and mixed integer linear programming optimization 659 techniques were used to solve the energy management problem. With this, a method to find 660 optimal battery size for the microgrid operating under mix-mode strategy was also presented. 661 The battery sizing problem was solved using the PSO optimization technique. The battery's 662 capital cost, its energy and power constraints, and distributed generator's operational limits were 663 taken into account while solving this problem.

664 Compared to other operating strategies, operating the microgrid under mix-mode operating 665 strategy would eventually reduce the microgrid's daily operating cost. Moreover, the proposed 666 battery sizing method was highly accurate in determining the optimal size of battery energy 667 storage for economic operation of the microgrid. The variation of the optimal battery capacity 668 with different sets of initial SOC levels was analyzed, and based on the analysis, it was found 669 that the optimal battery capacity increased as we selected lower initial SOC levels during the 670 start of the day. It was also found that the optimal battery capacity with higher initial SOC level 
671 reduced the microgrid's operating cost effectively with lower battery initial cost. Furthermore,

672 variation to the microgrid's operating cost against different SOC levels was analyzed. It was

673 found that as the initial SOC level during the start of the day was reduced, a significant reduction

674 in savings in the microgrid's operating cost became evident. Based on the results, a

675 recommendation on the choice of initial SOC level during the start of the day for an economical

676 operation of a microgrid was suggested. Finally, an analysis on variation of microgrid's

677 operating cost considering uncertainty in PV output power was carried out. It was found that the

678 availability of PV power from solar photovoltaic plant influenced the microgrid's operating cost

679 and battery source's operation.

680 Acknowledgements

681 This work is supported by the Ministry of Education, Malaysia under High Impact Research

682 Grant (HIR-MOHED000004-16001).

683 References

684 [1] S. Shivashankar, S. Mekhilef, H. Mokhlis, M. Karimi. Mitigating methods of power 685 fluctuation of photovoltaic (PV) sources-A review. Renewable and Sustainable Energy Reviews 686 2016; 59:1170-84.

687 [2] S. Koohi-Kamali, N. Rahim, H. Mokhlis. Smart power management algorithm in microgrid 688 consisting of photovoltaic, diesel, and battery storage plants considering variations in sunlight, 689

690 [3] C. Chen, S. Duan, T. Cai, B. Liu, G. Hu. Smart energy management system for optimal 691 microgrid economic operation. IET Renewable Power Generation 2011; 5:258-67.

692 [4] F.A. Mohamed, H.N. Koivo. Multiobjective optimization using Mesh Adaptive Direct Search 693 for power dispatch problem of microgrid. International Journal of Electrical Power \& Energy 694 Systems 2012; 42:728-35.

695 [5] F.A. Mohamed, H.N. Koivo. System modelling and online optimal management of microgrid 696 using mesh adaptive direct search. International Journal of Electrical Power \& Energy Systems $697 \quad 2010 ; 32: 398-407$.

698 [6] D. Tenfen, E.C. Finardi. A mixed integer linear programming model for the energy 699 management problem of microgrids. Electric Power Systems Research 2015; 122:19-28.

700 [7] H. Khodr, N. El Halabi, M. García-Gracia. Intelligent renewable microgrid scheduling 701 controlled by a virtual power producer: a laboratory experience. Renewable energy 2012; $702 \quad 48: 269-75$. 
[8] Xiongwen Zhang, Siew-Chong Tan, Guojun Li, Zhenping Feng. Components sizing of hybrid energy systems via the optimization of power dispatch simulations. Energy 2013; 52:165172.

[9] Y.-S. Cheng, M.-T. Chuang, Y.-H. Liu, S.-C. Wang, Z.-Z. Yang. A particle swarm optimization based power dispatch algorithm with roulette wheel re-distribution mechanism for equality constraint. Renewable energy 2016; 88:58-72.

[10] M. Kalantar. Dynamic behavior of a stand-alone hybrid power generation system of wind turbine, microturbine, solar array and battery storage. Applied Energy 2010; 87:3051-64.

[11] S. Mousavi G. An autonomous hybrid energy system of wind/tidal/microturbine/battery storage. International Journal of Electrical Power and Energy Systems 2012; 43:1144-54.

[12] S. Berrazouane, K. Mohammedi. Parameter optimization via cuckoo optimization algorithm of fuzzy controller for energy management of a hybrid power system. Energy Conversion and Management 2014; 78:652-60.

[13] S. Chen, H.B. Gooi, M. Wang. Sizing of energy storage for microgrids. IEEE Transactions on Smart Grid 2012; 3:142-51.

[14] B. Bahmani-Firouzi, R. Azizipanah-Abarghooee. Optimal sizing of battery energy storage for micro-grid operation management using a new improved bat algorithm. International Journal of Electrical Power \& Energy Systems 2014; 56:42-54.

[15] J.P. Fossati, A. Galarza, A. Martín-Villate, L. Fontán. A method for optimal sizing energy storage systems for microgrids. Renewable energy 2015; 77:539-49.

[16] C. Chen, S. Duan, T. Cai, B. Liu, G. Hu. Optimal allocation and economic analysis of energy storage system in microgrids. IEEE Transactions on Power Electronics 2011; 26:2762-73. [17] S. Sharma, S. Bhattacharjee, A. Bhattacharya. Grey wolf optimisation for optimal sizing of battery energy storage device to minimise operation cost of microgrid. IET Generation, Transmission \& Distribution 2016; 10:625-637.

[18] Y. Li, S. Rajakaruna, S. Choi. Control of a solid oxide fuel cell power plant in a gridconnected system. IEEE Transactions on Energy Conversion 2007; 22:405-13.

[19] X. Wang, B. Huang, T. Chen. Data-driven predictive control for solid oxide fuel cells. Journal of Process Control 2007; 17:103-14.

[20] K.A. Pruitt, R.J. Braun, A.M. Newman. Establishing conditions for the economic viability of fuel cell-based, combined heat and power distributed generation systems. Applied Energy 2013; 111:904-20.

[21] X. Tan, Q. Li, H. Wang. Advances and trends of energy storage technology in Microgrid. International Journal of Electrical Power \& Energy Systems 2013; 44:179-91.

[22] W. Gu, Z. Wu, R. Bo, W. Liu, G. Zhou, W. Chen, et al. Modeling, planning and optimal energy management of combined cooling, heating and power microgrid: A review. International Journal of Electrical Power \& Energy Systems 2014; 54:26-37.

[23] W. Al-Saedi, S.W. Lachowicz, D. Habibi, O. Bass. Power quality enhancement in autonomous microgrid operation using particle swarm optimization. International Journal of Electrical Power \& Energy Systems 2012; 42:139-49.

[24] Chee Wei Tan, Tim C.Green, Carlos A. Hernandez-Aramburo. A stochastic method for battery sizing with uninterruptible-power and demand shift capabilities in PV (photovoltaic) systems. Energy 2010; 35:5082-5092. 